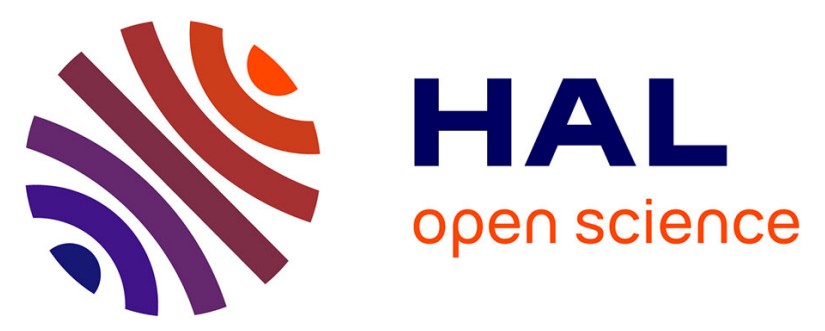

\title{
Lethal and sublethal effects of imidacloprid, after chronic exposure, on the insect model Drosophila melanogaster
}

Gaël Charpentier, Fanny Louat, Jean-Marc Bonmatin, Patrice A. Marchand, Fanny Vanier, Daniel Locker, Martine Decoville

\section{- To cite this version:}

Gaël Charpentier, Fanny Louat, Jean-Marc Bonmatin, Patrice A. Marchand, Fanny Vanier, et al.. Lethal and sublethal effects of imidacloprid, after chronic exposure, on the insect model Drosophila melanogaster. Environmental Science and Technology, 2014, 48 (7), pp.4096-4102. 10.1021/es405331c . hal-01178479

\author{
HAL Id: hal-01178479 \\ https://hal.science/hal-01178479
}

Submitted on 29 Sep 2021

HAL is a multi-disciplinary open access archive for the deposit and dissemination of scientific research documents, whether they are published or not. The documents may come from teaching and research institutions in France or abroad, or from public or private research centers.
L'archive ouverte pluridisciplinaire HAL, est destinée au dépôt et à la diffusion de documents scientifiques de niveau recherche, publiés ou non, émanant des établissements d'enseignement et de recherche français ou étrangers, des laboratoires publics ou privés.

\section{(c)(1)}

Distributed under a Creative Commons Attribution| 4.0 International License 


\title{
Lethal and Sublethal Effects of Imidacloprid, After Chronic Exposure, On the Insect Model Drosophila melanogaster
}

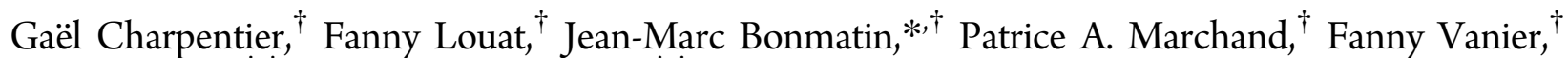 \\ Daniel Locker, ${ }^{\dagger \dagger}$ and Martine Decoville ${ }^{\dagger, \ddagger}$ \\ ${ }^{\dagger}$ Centre de Biophysique Moléculaire, Centre National de la Recherche Scientifique, 45071 Orléans, France \\ ‡Université d’Orléans, 45100 Orléans, France
}

ABSTRACT: Neonicotinoids are subjected to vigilance because of environmental
contaminations and deleterious effects on bees. Imidacloprid (IMI) is one of the most
representative insecticides of this family. At chronic exposure, concentration-effect
relationships are non linear. An insect model should allow a better description of this
toxicity. We compared the lethal concentration $50 \%$ (LC50) of IMI for a Drosophila-field
strain, after acute and chronic exposure. Relative to the acute LC 50 , the chronic LC 50 was
lowered by a factor of 29 for males $(1.3 \mathrm{mM} / 45 \mu \mathrm{M}), 52$ for larvae $(157 \mu \mathrm{M} / 3 \mu \mathrm{M})$ and
more than 172 for females ( $>3.1 \mathrm{mM} / 18 \mu \mathrm{M})$. Chronic exposure also revealed significant
lethal and sublethal effects, at concentrations $3-5$ orders of magnitude lower than the
chronic LC 50 . Mean mortalities reached $28 \%$ (at $3.91 \mathrm{nM})$ and $27 \%$ (at $39.1 \mathrm{nM}$ ) for
females and males, respectively. Fecundity decreased of $16 \%$ at $1.96 \mathrm{nM}$. Mating increased
of $30 \%$ at $0.391 \mathrm{nM}$. The LOEC (lowest observed effect concentration: $0.391 \mathrm{nM}$ ) was
46000 times lower than the chronic LC 50 for males; it was 115000 times lower than the
chronic LC 50 for females. This study illuminates effects that neonicotinoids can induce at
very low concentrations. This is of particular interest for nontarget insects and for insect dependent species.

\section{INTRODUCTION}

Most chemical pesticides are herbicides, fungicides, or insecticides. There is increasing interest to reduce their impacts on the environment, especially on nontarget species. Since the mid-1990s, the class of neonicotinoids has become the most widely used and fastest growing family of insecticides worldwide. $^{1-4}$ This neonicotinoid family includes imidacloprid, thiamethoxam, clothianidin, thiacloprid, acetamiprid, dinotefuran, and imidaclothiz. ${ }^{5}$ Neonicotinoid insecticides interact with the nicotinic acetylcholine receptors (nAChRs) of the central nervous system. They target and bind to postsynaptic nAChRs of insects and to their body cell nAChRs. ${ }^{4,6}$ They induce a neuronal hyper-excitation and accumulation of acetylcholine, leading to the insect's death within minutes. ${ }^{1}$ Generally, lethal doses induce to tetanic contractions, with intense trembling (legs), body convulsions and paralysis. This is accompanied by nerve and muscle destruction. ${ }^{7}$ They are significantly more selective toward insects than toward vertebrates. ${ }^{8,9}$ As a general fact, flying insects were found to be the most vulnerable species to neonicotinoid pesticides.

Imidacloprid (IMI), [1-(6-chloronicotinyl)-2-nitroimino-imidazolidine], is the archtypal member of representative chemical of the neonicotinoid insecticide family. ${ }^{3}$ IMI has a very high activity against insects and lethal doses 50\% (LD50) or lethal concentrations 50\% (LC50) are very low, by topical and oral exposures. The chemical structure of IMI ensures its diffusion within treated plants, by xylemic and phloemic transport. ${ }^{10}$ This systemic property gives IMI the advantage as a soil treatment and for treatment of seeds, with doses ranging from 50 to 100 $\mathrm{g} / \mathrm{ha}$, to protect the whole field.

The sublethal effects of IMI have already been studied in nontarget insects; ${ }^{11}$ mainly those of economic importance such as honey bees. ${ }^{12-16}$ However, relationships between effects and mechanisms of action are complex and difficult to establish. In order to better understand the effects of IMI, we used the drosophila model for which all parameters can be managed with confidence. The advantages of drosophila include a short life cycle as well as the efficiency and extensivity of tools about its genetics and genomics. Drosophila has already been used to investigate the genotoxic effects of pesticides such as IMI and acetochlor. $^{17}$

Our main goal was to identify and to differentiate concentration ranges where sublethal and lethal effects occur. The LC50 was first determined from acute exposure for larvae and adults (females and males) of a fruit fly strain fully managed in our laboratory. Chronic exposure over 8 days defined chronic LC50 for females and males. By investigating lower concentrations, additional effects on the survival, mating, and fecundity were characterized. 


\section{EXPERIMENTAL SECTION}

All experiments were conducted at $22{ }^{\circ} \mathrm{C} \pm 1{ }^{\circ} \mathrm{C}$. Test experiments (all tested concentrations of IMI) and controls were done in parallel (synchronicity). All experiments were performed over a 1.5 month period (March-April). All experiments were repeated at least six times. The number of flies tested for each data point is defined as $\mathrm{N}$.

Strain and Medium. A wild type stock of flies, named Orleans, derived from specimens caught in fields near Orléans (France) in 2000 and maintained in the laboratory by inbreeding, was used in this study. The stock of flies was maintained in our laboratory by mass culture at $22{ }^{\circ} \mathrm{C}$ on a standard medium. The composition for $4 \mathrm{~L}$ of standard medium was as follows: $362 \mathrm{~g}$ of cornmeal, $200 \mathrm{~g}$ of dry yeast (inactive and not hydrolyzed), $60 \mathrm{~g}$ of agar and $150 \mathrm{~mL}$ of a $10 \%$ solution of methyl-4-hydroxybenzoate (CAS number: 9976-3) in ethanol. All experiments were done with the same batch of cornmeal and yeast (Dominique Dutcher, Brumath, France).

Solvents, Reagents, and Chemicals. All solvents (acetone CAS number: 67-64-1, acetonitrile CAS number: 75-05-8, dimethyl sulfoxide CAS number: 67-68-5, methanol CAS number: 67-56-1, ethanol CAS number CAS number: $64-17-5$, and water CAS number: $7732-18-$ 5) were purchased from VWR (Fontenay-Sous-Bois, France) and are at least HPLC grade (ACS grade for DMSO). IMI (MW: $255.66 \mathrm{~g} / \mathrm{mol}$, Purity 99.5\%) was obtained from CIL Cluzeau (Sainte-Foy-la-Grande, France). The starting solution $(100 \mathrm{~g} / \mathrm{L})$ of IMI was prepared in DMSO as this solvent is a component of the commercial formulation ${ }^{18}$ and because solubility of IMI in water is relatively low. ${ }^{19}$ Other IMI solutions were obtained by dilution in distilled water. Test solutions of IMI were obtained by diluting this starting solution in water. DMSO was always present in test solutions and controls, at the same concentration, always lower than $1 \%(\mathrm{v} /$ v). Other reagents, such as salt compounds $\left(\mathrm{KH}_{2} \mathrm{PO}_{4}\right)$, were analytical grade and obtained from Aldrich (Saint-Quentin Fallavier, France).

Acute Toxicity. Males and females of three to four days old, in groups of about 20 flies, were transferred to vials without food for $6 \mathrm{~h}$, and then to vials containing a blotting paper moistened with a 5\% sucrose (CAS number: 57-50-1) solution with the tested concentration of IMI. Flies were left in these conditions for $18 \mathrm{~h}$. The control groups were fed with 5\% sucrose or $5 \%$ sucrose containing the same concentration of DMSO. For instance, DMSO was $1 \%(\mathrm{v} / \mathrm{v})$ for IMI $=3.91$ $\mathrm{mM}$; DMSO was $10^{-3} \%(\mathrm{v} / \mathrm{v})$ for IMI $=3.91 \mu \mathrm{M}$ and DMSO was $10^{-6} \%(\mathrm{v} / \mathrm{v})$ for IMI $=3.91 \mathrm{nM}$. After $18 \mathrm{~h}$, all flies were transferred into vials containing a standard medium. After 8 days, the flies still alive were counted. Series of ten concentrations, ranging from $7.8 \mu \mathrm{M}$ to $3.1 \mathrm{mM}$, were used for adults. Because we limited the DMSO content at less than $1 \%(\mathrm{v} / \mathrm{v})$, tests at higher concentrations were precluded.

To obtain the third-instar larvae, eggs were collected during a $3 \mathrm{~h}$ period and kept at $22{ }^{\circ} \mathrm{C}$. Four days later, groups of 20 larvae were transferred into individual Petri dishes containing agar $2 \%$ and some yeast paste prepared with a solution of IMI at the tested concentration. The larvae were transferred $18 \mathrm{~h}$ later into vials containing the standard medium. Larvae were kept on this medium and the surviving adults were counted. Control experiments were done with the same protocol but the yeast paste was prepared without IMI and with a solution where DMSO was at the same concentration as in the test solutions. Seven concentrations, ranging from $11.7 \mu \mathrm{M}$ to 0.5 $\mathrm{mM}$, were used for larvae.

Chronic Toxicity. Males and females were tested separately. Groups of 20 flies, 3-to-4 days old, were transferred into vials containing a fresh drosophila Instant Medium (DIM; Carolina Biological Supply, Burlington NC) prepared with distilled water containing the test IMI concentration ( $1.5 \mathrm{~g}$ rehydrated with $4.5 \mathrm{~mL}$ of test solution). Flies were kept in these vials continually. Flies, still alive 8 days later, were scored.

For larvae, the eggs were collected during a $3 \mathrm{~h}$ period. Immediately after hatching, larvae were transferred into vials containing fresh DIM rehydrated with the test solutions. Larvae were maintained on this medium, and the adults which emerged were counted. Control experiments for adults and larvae were done by using solutions at the same concentration of DMSO as the test solutions.

Mating Tests. Sets of five virgin males and sets of five virgin females (all flies $<6 \mathrm{~h}$ old) were randomly recovered from the stock in presence of IMI. They were placed into vials containing the fresh DIM with IMI. After 5 days, five females and five males were transferred without anesthesia into empty vials. These vials were observed for $20 \mathrm{~min}$ to determine how many females, in each vial, had mated. Note that this is the total duration of mating for drosophila. Because males and females used in this test were exposed to IMI during their rearing, we chose concentrations which allowed their larval development, far below the chronic LC50. Control experiments, using DMSO at the same concentration, were run in parallel. For consistency, $\mathrm{N}$ represents the number of females for mating tests.

Fecundity Tests. Virgin males and virgin females $(<6 \mathrm{~h}$ old) were randomly selected from the stock in presence of IMI and transferred in vials containing the fresh DIM with IMI. Males were raised individually and females were raised in groups of five flies per vial. After 5 days, one female and one male were transferred into a vial containing the standard medium. The vials were observed until the pair copulated, after which the male was removed. Each female could lay eggs for 24 $\mathrm{h}$ in this vial. Then the female was transferred into a new vial for $24 \mathrm{~h}$ where it could lay further eggs. This transfer was repeated five times. At the end, the female was transferred into a new vial where it could lay eggs until day 15 . Adult emergence was scored for all vials. We only used data from females that produced offspring. We checked that the number of females producing offspring were as numerous in test as in controls. As for the mating tests, we chose low concentrations. Control experiments, using DMSO at the same concentration, were run in parallel.

Analytical Measurements. Adult flies (4-to-5 days old) were starved for $6 \mathrm{~h}$ and were placed in a vial containing blotting paper moistened with the IMI test solutions. Immediately after the knockout effect, flies were frozen at $-80{ }^{\circ} \mathrm{C}$ by batches of 20 . Batches of flies (directly taken from the freezer) were ground in a glass test tube containing $1 \mathrm{~mL}$ acetonitrile with a Turrax 5G (IKA) for 2 min (twice). After evaporation of the solvents, the residue was transferred with acetone in order to proceed to a further purification step by SPE on Bond Elut $500 \mathrm{mg} / 3 \mathrm{~mL}$, purchased from Varian Inc. and conditioned with acetone $(2 \mathrm{~mL})$. The first five fractions were collected $(5 \times 5 \mathrm{~mL})$, evaporated and solubilized in 200 $\mu \mathrm{L}$ methanol. $50 \mu \mathrm{L}$ of this solution was then injected in a HPLC column through a rheodyne type valve. HPLC/UV analyses were performed, according to Obana et al., ${ }^{20}$ with a 
Merck apparatus (L-6200A Intelligent Pump; L-4000 UV detector; D-2500 Chromato Integrator) coupled with a C18 HPLC column, $3 \mu \mathrm{m}$ diameter $(250 \times 4.6 \mathrm{~mm}$ i.d. $)$ purchased from VWR. IMI was detected at $270 \mathrm{~nm}$ with a retention time of $18.4 \mathrm{~min}$. The calibration curve was calculated from 5 points $(1,10,100,400$, and $800 \mathrm{mg} / \mathrm{L})$, with $R^{2}=0.9988$.

Statistical Analyses. Data were statistically analyzed with the R software from R Core team (2013), R Foundation for statistical Computing, Vienna, Austria (http://www.R-project. org/). A general linear model (GLM) was used with a logistic link function (logit). The model has investigated main effects of (i) the IMI concentration, (ii) the sex of flies, and (iii) concentration-sex interactions, for survival data after chronic exposure. The model has investigated only the effect of IMI concentration for mating data. Additionally, comparison tests of independent proportions were used to identify significant differences between each experimental and control groups. For fecundity data, Mann-Whitney tests were used for comparisons. All these comparison tests were considered bilaterally, that is, considering the possibility of positive or negative effects. The statistical significance for all comparisons was set at $p<$ $0.05(*), p<0.01(* *)$, and at $p<0.001(* * *)$.

We also used Stat Graphics XV (15.2.14) from SIGMA PLUS (Levallois-Perret, France) to estimate the LC50 values and their $95 \%$ confidence interval (CI95). This was done by using the probit method developed by Finney. ${ }^{21}$

\section{RESULTS}

Acute Exposure. Survival. Insecticidal effects of IMI on larvae and adult drosophila were tested after acute treatment $(18 \mathrm{~h})$. In the control experiment (DMSO control), the average survival rate was $95 \%$ for adults and $82.5 \%$ for larvae. For adult females, a LC50 value was not determined, because only $31 \%$ of them died at the highest concentration used $(3.1 \mathrm{mM})$. This indicates the high resistance of the drosophila strain used in this study. In contrast, at the same concentration $(3.1 \mathrm{mM}), 91 \%$ of adult males were killed, allowing us to determine the corresponding LC50 value at $1304 \pm 92 \mu \mathrm{M}$ (Table 1).

Table 1. Lethal Concentrations 50\% (LC50 in $\mu \mathrm{M}$ ) of Imidacloprid for Drosophila melanogaster (Orléans Wild Strain)

\begin{tabular}{cccc} 
& \multicolumn{3}{c}{$\mathrm{LC}_{50}(\mu \mathrm{M})^{a}$} \\
\cline { 2 - 4 } mode of exposure & adult males & adult females & larvae \\
acute & $1304 \pm 92$ & $>3100^{b}$ & $157 \pm 25$ \\
chronic & $45 \pm 5$ & $18 \pm 1.5$ & $3.0 \pm 0.3$
\end{tabular}

${ }^{a}$ LC50 were calculated from sigmoid mortality curves. Mortalities were counted after 8 days following an acute exposure $(18 \mathrm{~h})$ or chronic exposure ( 8 days). The LC50 for adult flies (males and females) and for larvae were obtained with the same experimental conditions. The LC50 and their corresponding 95\% confidence intervals (CI95) were determined by probit analysis (see the Experimental Section). ${ }^{b}$ Estimated value because of the limited solubility of imidacloprid with respect to the experimental protocol.

For larvae, we did not discriminate between males and females. The number and gender of adults emerging were scored. No bias concerning female versus male was observed in the offspring, suggesting that the two sexes were equally killed by IMI at this larval stage. It should be noted that mortality induced by IMI occurred during the larval stages, as no lethality was observed in pupae stages. When compared to LC50 for adult males $(1.3 \pm 0.1 \mathrm{mM})$, the LC50 for larvae is 8 times lower $(157 \pm 25 \mu \mathrm{M})$, suggesting a higher acute toxicity of IMI for larvae.

Analyses of Flies. To estimate the residual amounts of IMI in insects, we performed measurements after intoxication of adults (of both sexes) at two IMI concentration levels (Table 2 ). Results were normalized with respect to mass ratio between

Table 2. Amounts of imidacloprid (in ng) per adult drosophila, measured by chemical analysis

\begin{tabular}{ccc} 
& \multicolumn{2}{c}{$\begin{array}{c}\text { imidacloprid content }(\mathrm{ng}) \\
\text { drosophila }\end{array}$} \\
\cline { 2 - 3 } feeding concentration $(\mathrm{mg} / \mathrm{L})$ & males & females \\
800 & $452 \pm 142$ & $475 \pm 111$ \\
333 & $184 \pm 24$ & $163 \pm 36$
\end{tabular}

${ }^{a}$ Chemical analyses were done following an acute exposure and after the knockout effect. ${ }^{b}$ Confidence intervals at 95\% (CI95), issued from statistical analysis, are reported.

male and female (1:1.4). We found the same amount of IMI in adult males and females, $452 \pm 142 \mathrm{ng} / \mathrm{male}$ and $475 \pm 111$ $\mathrm{ng} /$ female, respectively, this when feeding was done on solutions at $3.1 \mathrm{mM}(800 \mathrm{mg} / \mathrm{L})$. Values were $184 \pm 24 \mathrm{ng} /$ male and $163 \pm 36 \mathrm{ng} /$ female when feeding was done on solutions at $1.3 \mathrm{mM}(333 \mathrm{mg} / \mathrm{L})$. Thus, masses of IMI in males and in females were statistically equivalent and were proportional to the exposure levels.

Chronic Exposure. Survival. We first determined LC50 values. The control experiments (with DMSO) always displayed a survival rate over $94 \%$ for adults and it was over $83 \%$ for larvae. For the highest concentrations, results revealed typical sigmoid curves for which mortality increased sharply with concentrations (Figure 1). Table 1 shows LC50 values for adults and larvae. A distinction between sexes was made for adults. For adult males, the LC50 is $45 \pm 5 \mu \mathrm{M}$ instead of $18 \pm$ $1.5 \mu \mathrm{M}$ for adult females. These data indicate that females seem slightly more sensitive than males, after chronic exposure to IMI. The chronic LC50 was determined at $3 \pm 0.3 \mu \mathrm{M}$ for

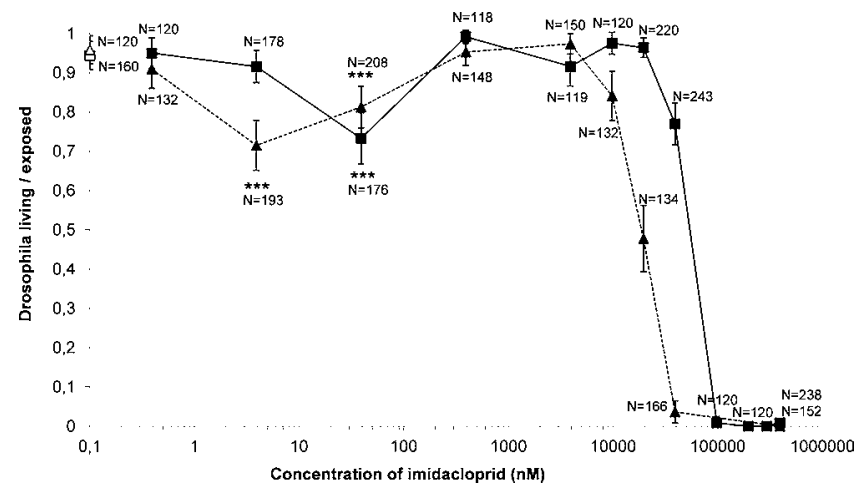

Figure 1. Average ratios of surviving drosophila after chronic exposure. Data are reported for adult flies: males $(\boldsymbol{\square})$ and females $(\boldsymbol{\Delta})$. Concentrations of imidacloprid ranged from $0.391 \mathrm{nM}$ to $0.391 \mathrm{mM}$. Ratios are given from the number of flies still alive, after chronic exposure to imidacloprid ( 8 days), over the number of flies exposed (see the Experimental Section). N: number of flies. Bars corresponding to $95 \%$ confidence intervals (CI95) are reported for each data point. Ratios for controls are indicated on the vertical axis: males $(\square)$ and females $(\triangle)$. Significant differences are indicated in the low concentration range only $(* * *$ when $p<0.001)$. 
larvae (Table 1). IMI is then more toxic (from 6 to 15 times) for larvae than for adults, after chronic exposure.

For adults we observed a particular shape of the survival curve, this shape seemed to be conserved between males and females but shifted with respect to the concentration scale (Figure 1). Statistical analysis (GLM) confirmed that there are significant effects of (i) the IMI concentration, (ii) the sex of flies, and (iii) the concentration-sex interactions. The shape (in form of V), showed a highly significant increase in mortality for females at $3.91 \mathrm{nM}$ and $39.1 \mathrm{nM}$, and for males at $39.1 \mathrm{nM}$ $(p<0.001)$. At these concentrations, the maximum value of mortality was $28 \%$ and $27 \%$ for females and males, respectively.

Mating. We studied the mating rate (during $20 \mathrm{~min}$ ) of sets of five couples after chronic exposure of flies during their whole life (larvae and adult). This was done between $0.0196 \mathrm{nM}$ and $391 \mathrm{nM}$ of IMI (Figure 2). Data suggested that IMI could

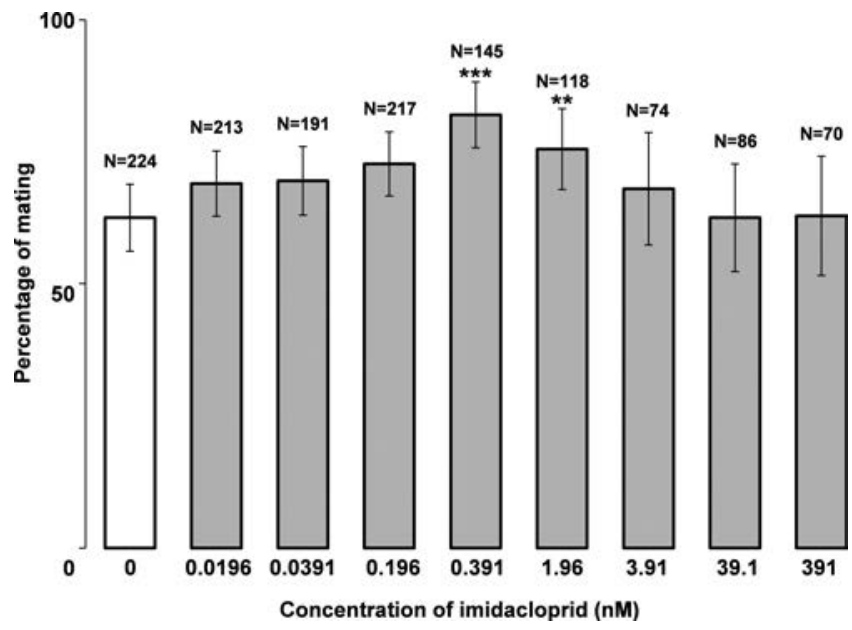

Figure 2. Average percentage of mating, depending on imidacloprid concentration. Mating was counted during a period of $20 \mathrm{~min}$, after chronic exposure to imidacloprid (see the Experimental Section). Concentrations of imidacloprid were between $0.196 \mathrm{nM}$ and $391 \mathrm{nM}$. For clarity, the horizontal axis has a non linear scale. Result for controls are given on the left (controls: white; tests: gray). $\mathrm{N}$ : number of females tested. Bars corresponding to $95 \%$ confidence intervals (CI95) are reported for each data point. Significant differences are indicated $(* * *$ when $p<0.001$ and $* *$ when $p<0.01)$.

induce an increase of the mating rate at $0.391 \mathrm{nM}$. At this concentration, the mean number of females which had mated within 20 min was 4.1, instead of 3.1 in the control experiment. However, statistical analysis (GLM) of all data points did not indicate any effect of IMI within this large concentration range. But, when comparing each data point with respect to the control, significant differences (30\%) were confirmed at 0.391 $\mathrm{nM}(p<0.001)$ and at $1.96 \mathrm{nM}(p<0.01)$.

Fecundity. We counted the number of offspring per female after chronic exposure of flies during their whole life (larvae and adult). This was done for various concentrations of IMI: from $0.391 \mathrm{nM}$ to $391 \mathrm{nM}$. A first set of experiments included both males and females exposed to IMI (Figure 3A). Here we observed a significant decrease in fecundity at $1.96 \mathrm{nM}$, $3.91 \mathrm{nM}$, and $39.1 \mathrm{nM}(p<0.05)$ when compared to controls. At a lower concentration $(0.391 \mathrm{nM})$ or at a higher concentration (39.1 nM or $391 \mathrm{nM}$ ), there was no significant statistical difference between controls and exposed flies. To assess the origin of this decrease in fecundity (effects on males or on females), we also exposed to IMI (3.91 nM) only males,
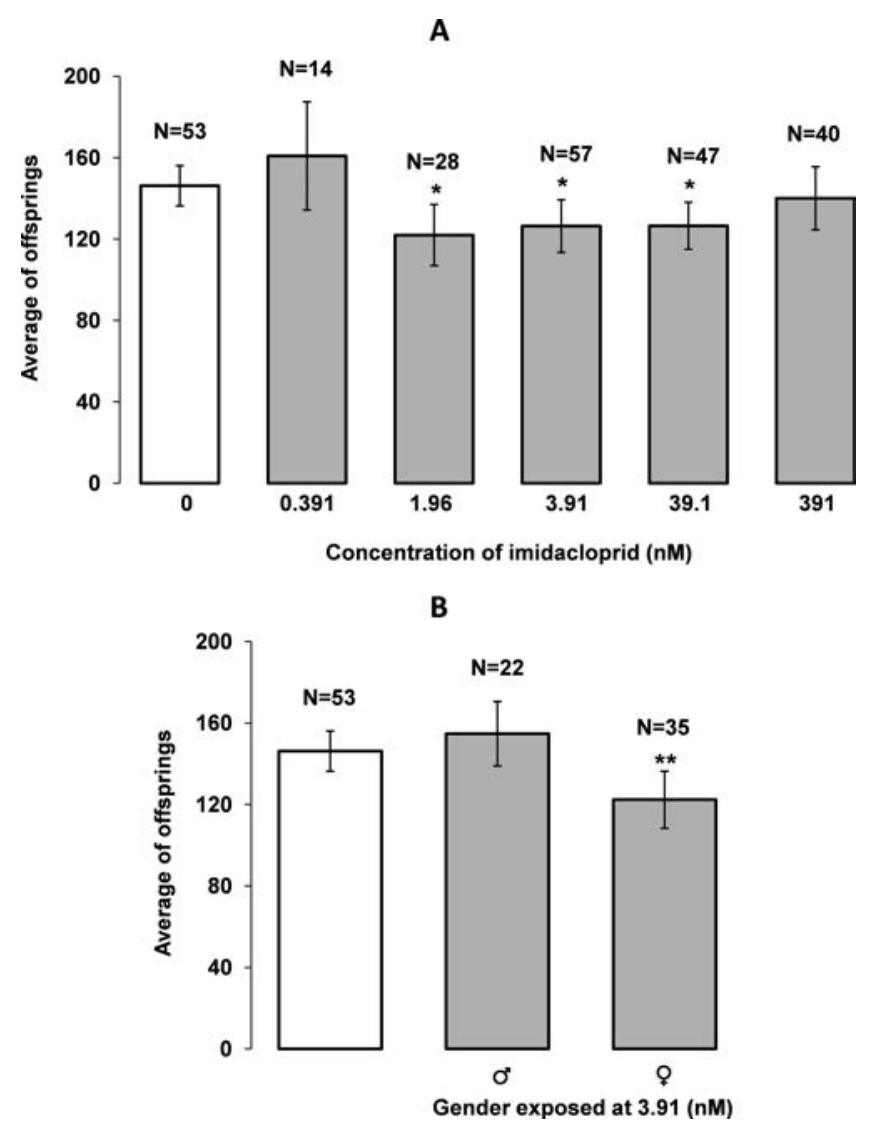

Figure 3. Average number of offsprings per female. Offsprings were counted after chronic exposure to imidacloprid (see the Experimental Section). Concentrations of imidacloprid were between $0.391 \mathrm{nM}$ and $391 \mathrm{nM}$. N: number of females tested. Bars corresponding to $95 \%$ confidence intervals (CI95) are reported for each data point. Significant differences are indicated $(* *$ when $p<0.01$ and $*$ when $p<0.05$ ). In (A), both male and female flies were exposed (controls: white; tests: gray). In (B), only one gender was exposed at a concentration of $3.91 \mathrm{nM}$ (controls: white; tests: gray; $0^{\star}:$ males; $\$$ : females).

or only females. The result showed that the decrease in fecundity can be attributed to the exposure of female flies only $(p<0.01)$, whereas there is no difference with control when only males were exposed (Figure $3 \mathrm{~B}$ ).

In order to better understand this decrease in fecundity, we compared the rate of hatching of embryos laid by control females, to that of exposed females. No significant difference was observed and about $95 \%$ of embryos had hatched into larvae in both cases. We also checked the possible lethality during larval or pupal stages. As matter of fact, no significant lethality was observed during these two developmental stages (data not shown).

\section{DISCUSSION}

Effects of IMI and LC50 (Acute and Chronic). We observed that the LC50 after chronic exposure was 29 times lower for adults and 43 times lower for larvae, when compared to an acute treatment (Table 1). In a previous paper which studied the genotoxic effects of IMI and of acetochlor in Drosophila melanogaster, the LC50 for IMI was determined after acute and chronic treatment on a mutant strain kept in laboratory. ${ }^{17}$ When comparing adults, the Orleans strain is more resistant to IMI than the mutant one. Here, the acute 
LC50 (adults) is 10 times higher than the value from Frantzios et al. In contrast, the chronic LC50 for adults of the Orléans strain is slightly lower than the chronic LC50 determined by the same authors (Orléans: $17.6 \mu \mathrm{M}$ for $\$$ and $44.9 \mu \mathrm{M}$ for $\sigma^{\star}$ versus $60 \mu \mathrm{M}$ for the mutant strain). Note that Frantzios et al. did not distinguish between males and females. Concerning larvae, the Orléans strain also appears more resistant after acute treatment (LC50 $157 \pm 25 \mu \mathrm{M}$ versus $75.5 \mu \mathrm{M}$ ), but less resistant after chronic treatment (LC50 $3 \mu \mathrm{M}$ versus $26.7 \mu \mathrm{M}$ ). The discrepancies observed between the two studies are probably explained by differences in the genetic background of each strain of flies. However, the Orléans strain appeared more resistant to mortality than the Oregon- $\mathrm{R}$ strain (data not shown) and as resistant as the Hikone- $\mathrm{R}$ strain, the latter one known to be resistant to DDT and IMI. ${ }^{22}$ It cannot be excluded that the Orleans strain could be issued from wild type flies selected for resistance from 1994 (introduction of IMI on the local market) to 2000.

Note that our study was performed in spring. It would be interesting to compare results obtained in various seasons and for various drosophila strains.

The analysis of the survival curves after chronic exposure revealed that, above $3.91 \mu \mathrm{M}$, mortality was directly related to the logarithm of concentrations (Figure 1). In this case, data have typical representations with sigmoid shapes and LC50 values were determined as mentioned above. However, it can be observed that more than one-fourth of flies died at $3.91 \mathrm{nM}$ (females) and $39.1 \mathrm{nM}$ (males). Three hypotheses can be mentioned related to these results. First, the processes of detoxification of IMI (for instance by cytochrome P450) would not be initiated so efficiently (concentration threshold) so a much larger fraction of the consumed IMI could reach the nAChRs. Second, IMI could bind to different receptors with different affinities (low and high affinity). Third, it cannot be excluded that a synergistic effect between DMSO and IMI could have occurred, but is unlikely because such a synergy (i) has little chance to only occur for very low amount of DMSO and (ii) has little chance to differ between males and females. However, data are still lacking to validate these hypotheses.

Differences of LC50 Depending on Fly Sex. In our experiments, females appeared more resistant than males after acute treatment. We tested the hypothesis that females could take less IMI than males. For this, we have determined the mass of IMI in the body of females and males. Therefore, we showed that the two sexes contained the same mass of IMI per insect (Table 2). Thus, we can make the reasonable assumption that both sexes have taken about the same quantity of IMI, although differences (amount, frequency) in food intake between the two sexes cannot be excluded. It is interesting to note that, when exposure was chronic, females are less resistant than males. Such a difference between sexes was also observed for various xenobiotics, as for example, caffeine, ${ }^{23}$ cycloheximide, ${ }^{24}$ endosulfan, and malathion ${ }^{25}$ or cypermethrin and fenvalerate. ${ }^{26}$

Differences of LC50 between Larvae and Adults. In larvae the LC50 was about 10-fold lower than the corresponding ones for adults, for both modes of intoxication, demonstrating a higher sensitivity of larvae to IMI (Table 1). An explanation is that larvae are in continuous contact with IMI during the experiment. Therefore, IMI could also diffuse through the integument and the digestive tract, leading to both topical and oral exposure. In contrast, IMI enters mainly through the digestive tract of adults. According to this hypothesis, a higher amount of IMI should be found in the larval body than in the adult body. Analyses were done, and we quantified IMI after acute exposure of larvae. The results suggested that the amounts of IMI were similar in larvae and adults. However, if results are normalized according to the body weight, for an identical feeding concentration, larvae were submitted to higher doses of IMI than the adults. Such a difference of exposure could account for the difference of LC50 between larvae and adults.

Sublethal Effects. Chronic exposure at very low concentrations of IMI showed significant effects on mating, with a maximum of $+30 \%$ at $0.391 \mathrm{nM}$ (Figure 2). It has been shown that the drosophila courtship is a behavior affected by experience during the first days of adult life. Moreover, nAChRs are exclusively neuronal in drosophila. ${ }^{27,28}$ Therefore, we can expect that exposure to very low doses, which affects neuronal plasticity during the early life, can result in alteration of the mating behavior. A similar effect has already been observed in drosophila after exposure to lead. ${ }^{29}$

Significant effects were also revealed when studying the fecundity after chronic treatment of both genders with IMI (Figure 3A). This decrease of fecundity (maximum 16\%) also displayed a shape in form of $\mathrm{V}$ and was linked to exposure of females only (Figure 3B). Several hypotheses can be proposed to explain this result. First, chronic exposure to IMI could affect oogenesis, as it is the case for cocaine. ${ }^{30}$ However, a first inspection of ovaries has not revealed evident anomalies of egg chambers. Second, exposure to IMI could indirectly induce some paralysis of the muscle fibers of the reproductive tract. However, Middleton et al. have demonstrated that the contraction in the drosophila ovary is under octopaminergic neuromodulation. ${ }^{31}$ Third, the continuous presence of IMI in the medium could alter the hormonal status of females and could affect egg production. For instance an increase of ecdysone reduces egg production. ${ }^{32}$

Finally, IMI induced sublethal effects and mortalities on this drosophila strain far below the LC50. This was substantiated when the exposure mode for larvae, or adults, was chronic. The lowest observed effect concentration (LOEC) was $0.391 \mathrm{nM}$ and concerned mating. LOEC was 4 orders of magnitude lower than the chronic LC50 for females. It was 5 orders of magnitude lower than the chronic LC50 for males. Such effects of IMI are certainly not restricted to our drosophila strain. For instance, there is also 5 orders of magnitude between the acute LC50 and significant mortalities after chronic exposure of bees over 10 days. ${ }^{33}$ Such effects are also consistent with the reduction of colony growth and the drastic reduction of queen production for bumble bees exposed to field-realistic concentrations of IMI. ${ }^{34}$

Implications and Perspectives. Drosophila melanogaster may be a convenient model for toxicity studies of chemicals such as IMI. It is convenient for determining chronic LC50 which is a relevant parameter for realistic exposure of non target species. It also allows time-to-effect studies which have been exemplified by Tennekes and Sanchez-Bayo for neonicotinoids ${ }^{35}$ in the cases of aquatic invertebrates and other arthropods. These latter studies are of particular importance because IMI can have direct effects on pollinators and birds ${ }^{36}$ or indirect effects on insectivorous species. ${ }^{37,38}$ In this view, two recent studies focused on adverse effects of neonicotinoids on large ecosystems including pollinators, aquatic species, and mammals. ${ }^{39,40} \mathrm{New}$ works for studying other nicotinoids and other systemic insecticides should be performed by using drosophila as a laboratory model. 


\section{AUTHOR INFORMATION}

\section{Corresponding Author}

*Phone: +33 (0)2 382555 87; fax: +33 (0)2 38631517; email: bonmatin@cnrs-orleans.fr.

Notes

The authors declare no competing financial interest.

\section{ACKNOWLEDGMENTS}

We thank the Conseil Général du Loiret (France) for their financial support. We acknowledge Bertin Pharma (Orléans) for their collaboration. We thank Franck Brignolas for his advices in statistics. We thank Patrice Robert for maintenance of drosophila strains. The authors thank the Task Force on Systemic Pesticides for fruitful discussions.

\section{REFERENCES}

(1) Tomizawa, M.; Casida, J. E. Neonicotinoid insecticide toxicology: Mecanism of selective action. Annu. Rev. Pharmacol. Toxicol. 2005, 45, 247-268.

(2) Brown, L. A.; Ihara, M.; Buckingham, S. D.; Matsuda, K.; Sattelle, D. B. Neonicotinoid insecticides display partial and super agonist actions on native insect nicotinic acetylcholine receptors. J. Neurochem. 2006, 99, 608-615.

(3) Jeschke, P.; Nauen, R.; Schindler, M.; Elbert, A. Overview of the status and global strategy for neonicotinoids. J. Agric. Food Chem. 2011, 59, 2897-2908.

(4) Buckingham, S. D.; Lapied, B.; Le Corronch, H.; Grolleau, F.; Sattelle, D. B. Imidacloprid actions on insect neuronal acetylcholine receptors. J. Exp. Biol. 1997, 200, 2685-2692.

(5) Wood, A. Compendium of Pesticide Common Names. http:// www.alanwood.net/pesticides/.

(6) Matsuda, K.; Shimomura, M.; Ihara, M.; Akamatsu, M.; Sattelle, D. B. Neonicotinoids show selective and diverse actions on their nicotinic receptor targets: Electrophysiology, molecular biology, and receptor modeling studies. Biosci. Biotechnol. Biochem. 2005, 69, 14421452.

(7) Mehlhorn, H.; Menke, N.; Hansen, O. Effect of imidacloprid on adult and larval stages of flea Ctenocephalides felis after in vivo and in vitro application: A light- and electron-microscopy study. Parasitol. Res. 1999, 85, 625-637.

(8) Matsuda, K.; Buckingham, S. D.; Kleier, D.; Rauh, J. J.; Grauso, M.; Satelle, D. B. Neonicotinoids: Insecticides acting on insect nicotinic acetylcholine receptors. Trends Pharmacol. Sci. 2001, 22, 573-580.

(9) Liu, G. Y.; Ju, X. L.; Cheng, J. Selectivity of Imidacloprid for fruit fly versus rat nicotinic acetylcholine receptors by molecular modeling. J. Mol. Model. 2010, 16, 993-1002.

(10) Bromilow, R. H.; Chamberlain, K.; Evans, A. A. Physicochemical aspects of phloem translocation of herbicides. Weed Sci. 1990, 38, 305-314.

(11) Kunkel, B. A.; Held, D. W.; Potter, D. A. Lethal and sublethal effects of bendiocarb, halofenozide, and imidacloprid on Harpalus pennsylvanicus (Coleoptera: Carabidae) following different modes of exposure in turfgrass. J. Econ. Entomol. 2001, 94, 60-67.

(12) Medrzycki, P.; Montanari, R.; Bortolotti, L.; Sabtini, A. G.; Maini, S. Effect of imidacloprid administered in sub-lethal concentrations on honey bee behaviour. Laboratory tests. Bull. Insect. 2003, $56,59-62$.

(13) Colin, M. E.; Bonmatin, J. M.; Moineau, I.; Gaimon, C.; Brun, S.; Vermandere, J. P. A Method to quantify and analyze the foraging activity of honey bees: Relevance to the sublethal effects induced by systemic insecticides. Arch. Environ. Contam. Toxicol. 2004, 47, 387395.

(14) Decourtye, A.; Deviliers, J.; Genecque, E.; Le Menach, K.; Budzinski, H.; Cluseau, S.; Pham-Delègue, M. H. Comparative sublethal toxicity of nine pesticides on olfactory learning performances of the honeybee Apis mellifera. Arch. Environ. Contam. Toxicol. 2005, $48,242-250$.

(15) Mommaerts, V.; Reynders, S.; Boulet, J.; Besard, L.; Sterk, G.; Smagghe, G. Risk assessment for side-effects of neonicotinoids against bumblebees with and without impairing foraging behavior. Ecotoxicology 2010, 19, 207-215.

(16) Henry, M.; Béguin, M.; Requier, F.; Rollin, O.; Odoux, J. F.; Aupinel, P.; Aptel, J.; Tchamitchian, S.; Decourtye, A. A common pesticide decreases foraging success and survival in honey bees. Science 2012, 336, 348-350.

(17) Frantzios, G.; Paptsiki, K.; Sidiropoulou, B.; Lazaridis, G.; Theophilidis, G.; Mavragani-Tsipidou, P. Evaluation of insecticidal and genotoxic effects of imidacloprid and acetochlor in Drosophila melanogaster. J. Appl. Entomol. 2008, 132, 583-590.

(18) Costa, C.; Silvari, V.; Melchini, A.; Catania, S.; Heffron, J. J.; Trovato, A.; De Pasquale, R. Genotoxicity of imidacloprid in relation to metabolic activation and composition of the commercial product. Mutat. Res. 2009, 672, 40-44.

(19) Kong, M. Z.; Shi, X. H.; Cao, Y. C.; Zhou, C. R. Solubility of imidacloprid in different solvents. J. Chem. Eng. Data 2008, 53, 615618.

(20) Obana, H.; Okihashi, M.; Akustu, K.; Kitagawa, Y.; Hori, F. Determination of acetamiprid, imidacloprid, and nitenpyram residues in vegetables and fruits by high-performance liquid chromatography with diode-array detection. J. Agric. Food Chem. 2002, 50, 4464-4467.

(21) Finney, D. J. The adjustment for a natural response rate in probit analysis. Ann. Appl. Biol. 1949, 36, 187-195.

(22) Daborn, P. J.; Yen, J. L.; Bogwitz, M. R.; Le Goff, G.; Feil, E.; Jeffers, S.; Tijet, N.; Perry, T.; Heckel, D.; Batterham, P.; Feyereisen, R; Wilson, T. G.; ffrench-Constant, R. H. A single p450 allele associated with insecticide resistance in Drosophila. Science 2002, 297, 2253-2256.

(23) Zimmering, S.; Kofkoff, R; Osgood, C. Survival of caffeine-fed adult males and females from strains of Drosophila melanogaster. Mutat. Res. 1977, 43, 453-456.

(24) Marcos, R.; Lloberas, J.; Creus, A.; Xamena, N.; Cabre, O. Effect of cycloheximide on different stages of Drosophila melanogaster. Toxicol. Lett. 1982, 13, 105-112.

(25) Creus, A.; Xamena, N.; Marcos, R. Sensitivity of different strains of Drosophila melanogaster to endosulfan and malathion. Toxicol. Lett. 1983, 16, 323-330.

(26) Batiste-Alentorn, M.; Xamena, N.; Velazquez, A.; Creus, A.; Marcos, R. Studies on the toxicity of cypermethrin and fenvalerate in different strains of Drosophila melanogaster Meig. (Insecta, Diptera). Environ. Res. 1987, 43, 117-125.

(27) Gundelfinger, E. D.; Hess, N. Nicotinic acetylcholine receptors of the central nervous system of Drosophila. Biochim. Biophys. Acta 1992, 1137, 299-308.

(28) Lee, D.; O’Dowd, D. K. Fast excitatory synaptic transmission mediated by nicotinic acetylcholine receptors in Drosophila neurons. J. Neurosci. 1999, 19, 5311-5321.

(29) Hirsch, H. V.; Mercer, J.; Sambaziotis, H.; Huber, M.; Stark, D. T.; Torno-Morley, T.; Hollocher, K.; Ghiradella, H.; Ruden, D. M. Behavioral effects of chronic exposure to low levels of lead in Drosophila melanogaster. Neurotoxicology 2003, 24, 435-442.

(30) Willard, S. S.; Koss, C. M.; Cronmiller, C. Chronic cocaine exposure in Drosophila: Life, cell death and oogenesis. Dev. Biol. 2006, 296, 150-163.

(31) Middleton, C. A.; Nongthomba, U.; Parry, K.; Sweeney, S. T.; Sparrow, J. C.; Elliott, C. J. Neuromuscular organization and aminergic modulation of contractions in the Drosophila ovary. BMC Biol. 2006, 4, 17.

(32) Bownes, M.; Scott, A.; Shirras, A. Dietary components modulate yolk protein gene transcription in Drosophila melanogaster. Development 1988, 103, 119-128.

(33) Suchail, S.; Guez, D.; Belzunces, L. P. Discrepancy between acute and chronic toxicity induced by imidacloprid and its metabolites in Apis mellifera. Environ. Toxicol. Chem. 2001, 20, 2482-2486. 
(34) Whitehorn, P. R.; O'Connor, S.; Wackers, F. L.; Goulson, D. Neonicotinoid pesticide reduces bumble bee colony growth and queen production. Science 2012, 336, 351-352.

(35) Tennekes, H. A.; Sanchez-bayo, F. (2011) Time dependant toxicity of nicotinoids and other toxicants: Implications for a new approach to risk assessment. J. Environ. Anal. Toxicol. 2012, S4-001.

(36) Lopez-Antia, A.; Ortiz-Santaliestra, M. E.; Mougeot, F.; Mateo, R. Experimental exposure of red-legged partridges (Alectoris rufa) to seeds coated with imidacloprid, thiram and difenoconazole. Ecotoxicol. 2013, 1, 125-138.

(37) Benton, T. G.; Bryant, D. M.; Cole, L.; Crick, H. Q. P. Linking agricultural practice to insect and bird populations: A historical study over three decades. J. Appl. Ecol. 2002, 39, 673-687.

(38) Peach, W. J.; Vincent, K. E.; Fowler, J. A.; Grice, P. V. Reproductive success of house sparrows along an urban gradient. Anim. Conserv. 2008, 11, 493-503.

(39) van der Sluijs, J. P.; Simon-Delso, N.; Goulson, D.; Maxim, L.; Bonmatin, J. M.; Belzunces, L. P. (2013) Neonicotinoids, bee disorders and the sustainability of pollinator services. Curr. Opin. Environ. Sustainability 2013, 5, 1-13.

(40) Mason, R.; Tennekes, H.; Sanchez-Bayo, F.; Jepsen, P. U. Immune suppression by neonicotinoid insecticides at the root of global wildlife declines. J. Environ. Immunol. Toxicol. 2013, 1, 3-12. 